\title{
Sensors: From Biosensors to the Electronic Nose
}

\author{
By Diego L. García-González and Ramón Aparicio \\ Instituto de la Grasa \\ Avda. Padre García Tejero, 4, 41012 Sevilla Spain \\ E-mail: dluisg@cica.es
}

\section{CONTENTS}

1. Introduction

2. Sensory quality.

3. Sensors.

3.1. Metal oxide semiconductor sensors (MOS).

3.2. Metal oxide semiconductor field-effect transistor (MOSFET) sensors.

3.3. Conducting polymer sensors.

3.4. Acoustic sensors.

3.5. Biosensors.

4. The electronic nose.

5. The electronic tongue.

6. Data analysis.

6.1. Pre-processing data analysis.

6.2. Multivariate data analysis.

6.2.1. Cluster analysis.

6.2.2. Factorial analysis.

6.2.3. Discriminant analysis.

6.2.4. Regression analysis.

6.3. Artificial neural networks.

References.

\section{RESUMEN}

Sensores: De los biosensores a la nariz electrónica.

Los recientes avances en los sistemas de sensores han permitido el desarrollo de nuevas aplicaciones en muchos campos tecnológicos. Este artículo de revisión describe el estado actual de esta nueva tecnología, con especial énfasis en las aplicaciones alimentarias. El diseño, la tecnología y el mecanismo sensorial de cada tipo de sensor son analizados en el artículo. También se describen las principales características de la nariz y la lengua electrónica (sensores de sabor). Finalmente, se describe brevemente el uso de algunos procedimientos estadísticos en sistemas de sensores.

PALABRAS-CLAVE: Athe nálisis sensorial - Biosensores Nariz electrónica - Sensores.

\section{SUMMARY}

\section{Sensors: From Biosensors to the Electronic Nose.}

The recent advances in sensor devices have allowed the developing of new applications in many technological fields. This review describes the current state-of-the-art of this sensor technology, placing special emphasis on the food applications. The design, technology and sensing mechanism of each type of sensor are analysed. A description of the main characteristics of the electronic nose and electronic tongue (taste sensors) is also given. Finally, the applications of some statistical procedures in sensor systems are described briefly.

KEY-WORDS: Biosensors - Electronic nose - Sensors -Sensory analysis.

\section{INTRODUCTION}

For ages, there has been much interest in the design of devices for the sensing of food flavour. The devices, or instruments, are claimed to operate on principles similar, in many aspects, to the human olfactory system. Today, the methodologies devoted to the sensory assessment of foodstuffs are based on either the classical panels of trained human beings or the analysis of some chemical compounds by headspace-gas chromatography (-mass spectrometry) or the global evaluation of the odour intensity of volatile compounds by the emergent sensor technologies.

The experts' panel, usually the only official method for the sensory evaluation, allows the sensory qualification of foodstuffs by their own potential consumers, as well as the evaluation of all the sensory perceptions in only one analysis. It has, however, the great disadvantage of being a lengthy and expensive methodology whose final result depends on many factors as, for example, the panellists' training and the specific vocabulary used in the sensory analysis.

An alternative method is the identification and quantification of the chemical compounds responsible for the sensory perceptions. Non-volatile compounds are mainly focused on phenolic compounds and aglycons, responsible for tasting perceptions (astringent, bitter and pungent) (Morales and Tsimidou 2000), while volatile compounds are responsible for the aroma of foodstuffs (Aparicio et al. 1996). The first set of compounds is quantified by high performance liquid chromatography (HPLC) (Montedoro et al. 1992) while the quantification of volatile compounds can be carried out by various analytical techniques (Morales et al. 1992). The latter can be summarised as:

1. those not involving concentration:

- direct injection.

- static headspace

2. those with concentration-distillation.

- simultaneous distillation-extraction.

- dynamic headspace/purge-and-trap.

- supercritical fluid extraction.

- solid phase micro extraction 
The usefulness of these techniques in sensory analysis is based on the fact that volatile compounds are responsible for the foodstuff odours. Thus, an interesting approach has been carried out in virgin olive oil to establish the relationships between volatile compounds and flavour (Aparicio et al. 1996), and between phenols and taste (Morales and Tsimidou 2000) using the mathematical algorithm of the statistical sensory wheel (Aparicio et al. 1994).

These techniques can assess the sensory quality routine tests but cannot be used on-line because they are time-consuming and they previously need of a sample pre-treatment or a volatile concentration phase.

An alternative, recently developed, is the use of sensors that have been widely used in many fields of analytical chemistry. Conceptually speaking, this kind of sensor is a device that is able to give a signal proportional to the physical or chemical property to which the device responds (Kress-Rogers 1997); for example, the sensors transduce the signals produced by magnetic, thermal and chemical fields. Based on these facts, the most common definition is that a sensor is a single transducer in which, due to a physical effect, a complete transduction process takes place (Middelhoek 2000). The electronic integration of various sensors inside one set constitutes an array of sensors, or the so-called electronic nose, that is the kind of low cost structure habitually used to analyse the aroma of the foodstuffs.

The sensors have some advantages over other cited techniques. They do not use reagents or need of any kind of pre-treatment, they have good levels of sensitivity and specificity, and besides they are rapid supplying results to the analyst. This is a non-destructive technique that can be used in an on line quality control during the manufacturing process. But sensors have obviously disadvantages mainly focused on the reproducibility, recovery, and the effect that humidity and temperature have on the sensor responses. The analysis of these aspects, advantages and disadvantages of the sensor technologies, together with the applications of the different kinds of sensors in food science are the objectives of this review. Finally, there is a schematic analysis of the mathematical procedures used to analyse the sensor results as well as the application fields and the references.

\section{SENSORY QUALITY}

Sensory quality consists on a set of quality attributes, that can be detected through sense organs, like appearance, size and shape, colour, viscosity, kinesthetic sensations, tactile sensations, and chemesthetic sensations (stimuli elicited from some chemical irritants), odour and taste (Angerosa

\section{Table I \\ Application of the sensory panel in different critical points of the food industry}

Monitoring of the food ripening (e.g., wine, cheese)

Quality assurance of the selected raw foods

Monitoring of the cooking processes

Monitoring of the fermentation processes

Monitoring other industrial processes (e.g., flavouring,

blending, colouring).

Monitoring the storage of foods and food products

(e.g., freshness and ageing control)

Quality assurance of the manufactured food products

Monitoring of the product-packaging interactions

Monitoring of the overall quality of the final food or food product.

2000). Colour and flavour are, however, the sensations that mainly contribute to food acceptability by consumers (Morales and Tsimidou 2000) or when monitoring food industry processes (Table I). Flavour is a complex sensation consisting primarily of odour and taste, but is complemented by tactile and kinesthetic sensations (Reineccious 1993). The importance of flavour in the global sensory quality lies in the fact that it plays a crucial role in food recognition, selection, acceptance and nutrition, as it is partly responsible for aiding the digestion of food humans (Ensor 1989).

The main human sensor contributing to flavour is the olfaction system that detects the odorant compounds. The basic characteristics of odorant molecules are to have low relative molecular masses (up to approximately $300 \mathrm{Da}$ ), to be small and polar, and also to be hydrophobic (Craven et al. 1996). In the nasal mucus, there are small odourant binding proteins (OBPs) that accommodate the hydrophobic molecules in solution (Breer 1997). The OBPs work as binders of the odourant compounds and starters of the transduction reaction. After crossing the mucus layer, the odourants reach the chemosensory ciliary membrane of the olfactory neuron in which the G-receptor proteins are located (Gardner and Bartlett 1994). More than 100 million olfactory cells with these receptor proteins are inside the olfactory epithelium. The receptors interact with odourant molecules and generate a second set of messengers that cause excitation in the neurones. The signal is processed in the olfactory bulb and then the information is transmitted to the limbic system where the associations between odour information and recalled memories take place (Keller et al. 1999). The information of the receptors is also transmitted to the cerebral cortex where is combined with the taste to produce the flavour sensation.

On the other hand, the taste receptors are mainly situated on the tongue surface, over the entire oral 
cavity, down the oesophagus and even on the trachea and larynx. When an appropriate soluble substance reaches the taste cell, the interaction of the molecule with the G-receptor protein leads to chemical changes that result in a neural impulse (Winquist et al. 1999). The result is the tasting perception that has four basic tastes (bitter, sweet, salt and sour) although the sensory assessors are able to distinguish between dozens of different tastes, for instance qualifying virgin olive oil (Aparicio et al. 1994).

\section{SENSORS}

Today, several commercial sensors are available on the market besides the great number of prototype sensors that are being designed by research institutions year by year. All these types of sensors exhibit physical and chemical interactions with the chemical compounds when they flow over, or are in contact with, the sensors. The choice of sensors is hence quite large, so that we have classified them into broad classes following an arborescent structure. The odour sensors, tasting sensors and biosensors, constitute the first set. The latter two groups are the result of a very recent research, and hence there is not a taxonomic structure for these sensors yet. The sensors of the former group can however be clustered into two great groups according to their working temperature: hot sensors and cold sensors. The group of the so-called "hot sensors" mainly clusters the different kinds of metal oxide gas sensors (based on doped or undoped semiconductors), while the group of the "cold sensors" clusters the piezoelectric crystal sensors (bulk acoustic wave sensors, surface acoustic wave sensors) and the conducting organic polymer sensors. Figure 1 shows schematic diagrams of the

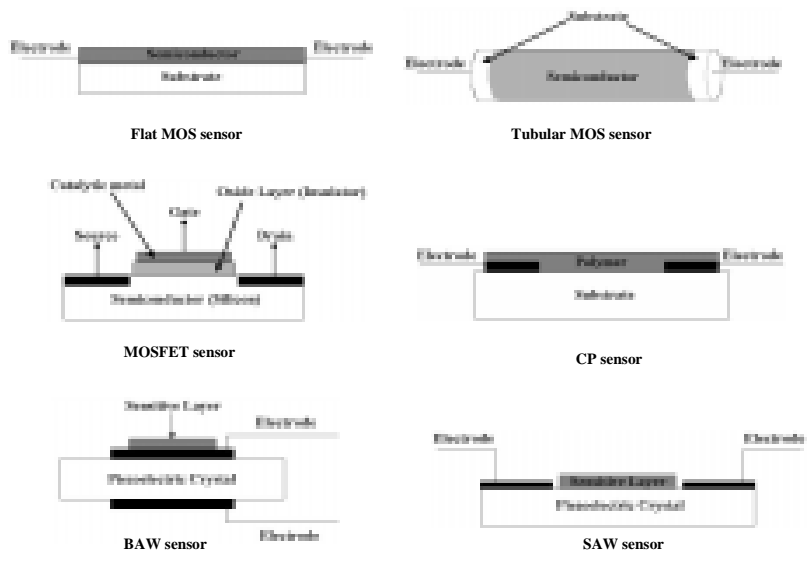

Figure 1

Schematic diagrams of the main odour sensors: Flat and tubular metal oxide semiconductor (MOS), metal oxide semiconductor field effect transistor (MOSFET), conducting polymer (CP), bulk acoustic wave (BAW) and surface acoustic wave (SAW) sensors. main odour sensors while Table II shows the physical responses of these sensors to the concentration of volatile compounds. When the analysts work with an array of sensors of the same class (e.g., metal oxide gas sensors made with doped plus undoped semiconductors) or combining different classes (e.g., conducting polymer sensors plus piezoelectric crystal sensors), the resulting instrument is habitually called "electronic nose". Furthermore, Winquist et al. (1999) have recently gone beyond describing the combination of an electronic nose and an electronic tongue.

\subsection{Metal oxide semiconductor sensors (MOS)}

These sensors are the most commercially extended in the sensing systems. They consist of a ceramic former (tubular or flat) heated by wire and coated with a metal oxide semiconducting film. For this reason, they are usually called metal oxide, or ceramic, gas sensors (Schaller et al. 1998) although they can also be called Taguchi and Figaro because of the inventor and the first company respectively. The oxide coating may be either n-type or p-type semiconductors. The n-type semiconductor $\left(\mathrm{SnO}_{2}\right.$, $\mathrm{ZnO}, \mathrm{In}_{2} \mathrm{O}_{3}, \mathrm{WO}_{3}, \mathrm{Fe}_{2} \mathrm{O}_{3}, \mathrm{Ga}_{2} \mathrm{O}_{3}, \mathrm{TiO}_{2}$ ) responds to oxidising compounds and its thermal or photolytic excitation results in an excess of electrons that increases the reactivity with oxidising molecules. The p-type semiconductor (oxides of nickel or cobalt) responds to reducing compounds and its excitation promotes reactions with reducing compounds due to an electron deficiency in its valence band. These metal oxides (mostly $\mathrm{SnO}_{2}, \mathrm{Ga}_{2} \mathrm{O}_{3}$ and $\mathrm{TiO}_{2}$ ) can also be doped with metals such as $\mathrm{Cu}$ (Zhang and Liu 2000), Pt plus Nb (Comini et al. 2000) and Sb, Bi, Fe, $\mathrm{Au}, \mathrm{Cd}$ (Morimitsu et al. 2000), or metal oxides of Co, $\mathrm{Cr}$, La, Ce (Fukui and Katsuki 2000), Mg, Al (Xu et al. 2000), Ru, Rh and Ir (Lang et al. 2000) among others. These doping metals help to diminish the humidity and temperature dependence (Fukui and Katsuki 2000; Morimitsu et al. 2000), and to improve the sensitivity and the selectivity (Comini et al. 2000; Mielle 1996).

Table II

\section{Physical properties of the sensors described in the review}

\begin{tabular}{ll}
\hline \multicolumn{1}{c}{ Sensor } & \multicolumn{1}{c}{ Physical property } \\
\hline Metal-oxide sensors (MOS, MOSFET) & Resistance and impedance \\
Conducting polymer sensors & Resistance and impedance \\
Electrochemical sensors & Conductance, intensity and voltage \\
Acoustic sensors (SAW, BAW, QMB, & Mass and frequency shift \\
Cantilever) & \\
Calorimetric sensors & Temperature \\
Optical sensors & Optical properties \\
\hline
\end{tabular}


The metal film thickness further classifies sensors into thin film (6-1000 nm) and thick film (10-300 $\mu \mathrm{m})$ sensors. The thickness is only related to the technique used (physical or chemical vapour deposition for thin films versus screen printing or painting depositions for thick films) but also with the response (faster for thin films), sensitivity (higher for thin films), and reproducibility (higher for thick films) and cost (much more low for thick films). The screenprinting techniques, based on a planar integrated microelectronic technology, allow obtaining low size sensors with high performance in various application fields. Nevertheless, screen-printed ceramic gas sensors need improvements as lowing the power consumption, getting best selectivity and facilitating mounting technology. These aspects are reached with micromachined metal oxide gas sensors, where sensitive layer is deposited in a thin dielectric film of low thermal conductivity, getting isolation between substrate and gas sensitivity heated area (Simon et al. 2001).

The mechanism of sensing of these sensors is related to the semiconductor behaviour when exchanging oxygen between the volatiles and the metal film. In non-operating, when only the carrier gas (e.g., synthetic air) flows in the sensor chamber, the oxygen is adsorbed on the surface and inside the metal coating, filling the sensor lattice vacancies, and later oxygen attracts free electrons from the semiconductor material with which the sensor conductance increases. In operation, when the interactions between adsorbed volatile molecules and metal film take place, the conductance decreases due to the reaction with the adsorbed oxygen. Two mechanisms, that can occur simultaneously, have been described in this phase (Schaller et al. 1998). At relatively low temperatures, when reducing volatiles compounds are adsorbed on the surface, the charges are transferred between the volatiles and adsorbed oxygen. At high temperature, however, the loaded oxygen reacts with the adsorbed volatile compounds, and conductance decrease in a non-linear manner. Zhang and Liu (2000) have studied the particular cases of $\mathrm{NO}_{2}$ and $\mathrm{CO}_{2}$ over various transition metals. Furthermore, the authors have suggested some mechanisms that produce more oxygen vacancies in the material, leading to a decrease in the free electron concentration and an increase in sensitivity of the material (e.g., the substitution of tin ions for copper ions).

Recently other measurement parameters have been studied, in addition to the electrical resistance change. The temperature drop during the sensing reaction has been proposed (Liu et al. 2000; Takada 2000). The temperature decrease is caused by a change in the thermal conductivity of the sensors and it is related to the reaction between reducing gases and surface oxygen ad-ions. They have a working temperature between $200^{\circ} \mathrm{C}$ and $400^{\circ} \mathrm{C}$ (Simon et al. 2001), and the organic volatiles are completely combusted to water and carbon dioxide when settles the sensor surface.

These small size sensors are robust, they have a quite good sensitivity, their signal processing is simple, and they have a very low cost (Simon et al. 2001). Their sensitivity is, however, affected by humidity and poisoning materials. Although the sensors are made of materials relatively resistant to humidity and ageing, the humidity is still the main problem as the sensor sensitivity decreases when humidity increases. Another drawback is the possibility of the sensor poisoning by sulphur compounds (e.g. $\mathrm{H}_{2} \mathrm{~S}$ or $\mathrm{SO}_{x}$ ) that produces the total or partial irreversible destruction of the sensor. Sulphur is known as an inhibitor for metal and oxide catalysts. On metals, sulphur chemisorbs an unoccupied orbital of the metal via its occupied lone pair orbital, while, on oxides, sulphur is substituted for lattice oxygen atoms. This irreversible process can be caused by the presence of sulphur compounds or some acids (e.g. acetic) in the samples, e.g. cheeses, wines, vinegars, cruciferous vegetables or lampant virgin olive oils. Ethanol also affects to sensor but only producing a temporary blinding effect to any other analytes present in the sample. Other undesirable characteristics of these sensors are: their slow baseline recovery when compounds with high molecular weight are analysed, their high working temperature that makes them inappropriate in environments containing flammable chemicals, their poor specificity and selectivity, and the sensor drift mainly caused by sensitivity loss.

Most of the metal-oxide sensors show a non-linear response to a given chemical compound or odour. Several attempts to find a satisfactory

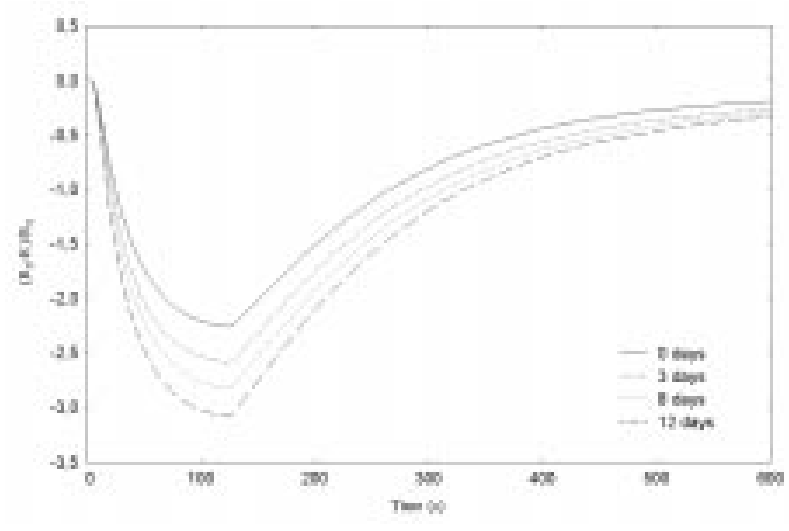

Figure 2

Responses of a MOS sensor (Alpha MOS 4000) to virgin olive oils characterised by different levels of oxidation. Oxidized olive oil samples were prepared placing virgin olive oil samples in the beam of an ultraviolet light for different days ( $0,3,8,12$ days). 
relation between the sensor responses and the analyte concentration or the odour intensity have been done. The formula $R=1 / A C^{\alpha}$ (where, $R$ is the response intensity, $A$ and $\alpha$ are constant, and $C$ is the concentration) has been proposed to explain the sensor response at moderate concentration and below the saturation level of the sensor (Wilson et al. 2000). Khol et al. (2000) have also expressed the sensor response as $\mathrm{R}-\mathrm{R}_{0} / \mathrm{R}_{0}=K(C)^{1 / 2}$ (where $\mathrm{K}$ is a sensor-dependent constant). Mielle et al. (2000) have found another relation between the compound concentration and the sensor response: $R-R_{0} / R_{0}=10^{(a+b) \log c}$, where "a" and "b" are constants for each compound.

The application of these sensors has been mainly focused on the detection of gas leakage, combustible and toxic gases (Shurmer and Gardner 1992; Xu et al. 2000; Ménil et al. 2000; Simon et al. 2001) but their applications on food technology have always been of relevance. Thus, these sensors have been applied to detection of volatile compounds of different foodstuffs as coffee (Gardner et al. 1992), milk (Sberveglieri et al. 1998), strawberry (Hirschfelder et al. 1998), juices (Bazemore et al. 1997), meat (Braggins et al. 1999) and edible oils (Bazzo et al. 1998). Figure 2 shows the responses of a MOS sensor (AlphaMOS 4000) to virgin olive oils characterised by different levels of oxidation.

\subsection{Metal oxide semiconductor field-effect transistor (MOSFET) sensors}

These sensors comprise three layers, a silicon semiconductor, a silicon oxide insulator and a catalytic metal $(\mathrm{Pd}, \mathrm{Pt}, \mathrm{Ir}, \mathrm{Rh})$ called the gate (Schaller et al. 1998). This design corresponds to the transistors designed by Lundström in 1975 (Middelhoek 2000). This kind of transistors operates by means of three contacts, two allow the current in (source) and out (drain), and third acts as the gate and regulates the current through the transistor. When a voltage is applied on the gate, an electric field is generated which affects the transistor conductivity. If vapour (polar compounds) interacts with the gate, then the current flowing through the transistor (sensor) changes and a shift of the conductance is produced. The interaction between the vapour and the gate depends on the gate structure; it can be thin, made of a porous metal film (6-20 nm), or thick, built with a dense metal film (100-200 nm). The latter kind of gate (transistor) works well with vapours containing molecules that can dissociate hydrogen, because these atoms lead to a potential change in this kind of transistor. Almost all kind of compounds, however, respond well when the gate is thin, due to the probable mechanisms of voltage shifts described by Lundström et al. (1975; 1990) and Spetz et al. (1992).
MOSFET are robust sensors with low sensitivity to humidity but whose selectivity and sensitivity can be affected by the working temperature $\left(75-200^{\circ} \mathrm{C}\right)$, kind of metal gate (as described) and microstructure of the catalytic metal. Their robust characteristic makes them particularly useful in environmental applications (Spetz et al. 2000). They show good sensitivity to toxic and flammable substances (Zhao et al. 2000) and because of their sensitivity to ethanol they are also used in food cooking, fermenting, and wine-making processes (Zhao et al. 2000). Finally, these sensors have been used for the ethylene measurement during fruit ripening process (Winquist et al. 1990).

\subsection{Conducting polymer sensors}

Since Diaz et al. (Persaud and Travers 1997) designed the first polypyrrole sensor, the interest in conducting polymers (CPs) has increased year by year. These sensors are made of a broad range of monomers that are polymerised by chemical or electrochemical methods. A thin film of polymer is deposited onto a sensing substrate formed by two parallel platinum or gold plated electrodes with a insulating base such as oxidized silicon (Partridge et al. 1996). The most common polymers used in the synthesis of CPs are polypyrroles, polyanilines, polytiophenes, butane to decane sulphonic acids, para-toluenesulphonic acid and its tetra-ethylammonium salt, sodium monohydrogenosulphate and tetraethylammonium tetrafluoroborate (Mielle 1996) although new polymers are being synthesized to open these sensors to new applications. Thus, polymers with a conjugated bonding system are being now used due to the excellent electrical characteristics of these materials for microelectronic device manufacturing (Rella et al. 2000). Sensors based on aniline and derivates can be doped at specific ratios with other compounds, as sulphonic acids (Koul et al. 2001) or HCl (Campos et al. 2000), so enhancing their electrical-optical properties and solubility in organic solvents. The dopants provide extra charges in the chain of the polymer with the formation of charged defects, such as spinless bipolarons (Rella et al. 2000) or small regions of positive charge in the polymer chain that provide mobile holes for electron transport.

The CP sensing characteristics are based in a measurable change in the electrical conductivity when CPs are exposed to volatile compounds. A fixed voltage among the electrodes produces a constant current that passes through the conducting polymer. When gas flows on the sensor, the volatile compounds adhere to its surface, and an adsorptiondesorption process occurs on the polymer layer which alters the electron flow in the system and hence the sensor conductivity. Therefore these 
changes in conductivity are based in the mobility of charges along the conjugation of the $\pi$-backbone of the polymer. Counterions (stabilised ions that are put inside the polymer by the manufacturer in order to balance other charges inside the microstructure of polymer layer) can produce some modifications such as changes in morphology of polymer-dopant complex, in the concentration of chemical defects (polarons or bipolarons) or the oxidation state of the polymer (Tan and Blackwood 2000) although the operating mechanism is not yet well understood. Spectral studies, as UV-VIS spectroscopy, FTIR spectroscopy, and electron spin resonance spectroscopy (ESR), are being carried out to know more about the interactions occurring during the sensing process (Tan and Blackwood 2000; Koul et al. 2001).

The sensor characteristics explain why they are ones of the most used in sensor arrays. They are easily fabricated, their power consumption is low, and they are robust and can work at room temperature. As it is said above, there are many types of polymers, including a broad range of derivates, and more types of polymers appear each year. The nature of the dopants also modifies their initial properties (Koul et al. 2001), and it means the possibility of designing sensors tailored to specific series of volatiles (e.g. ketons, aldehydes or alcohols) or towards a particular application (e.g. characterisation or authentication). The oxidation state of the polymer can also be changed after deposition to tailor the sensing characteristics (Partridge et al. 1996). CPs are resilient to poisoning by the compounds that inactivate the described inorganic semiconductor sensors but surprisingly their lifetime, only about 9-18 months, is shorter.

The random nature of the deposition process is, however, a problem for the production of reproducible sensors, although the use of four electrodes, instead of two, seems to improve the

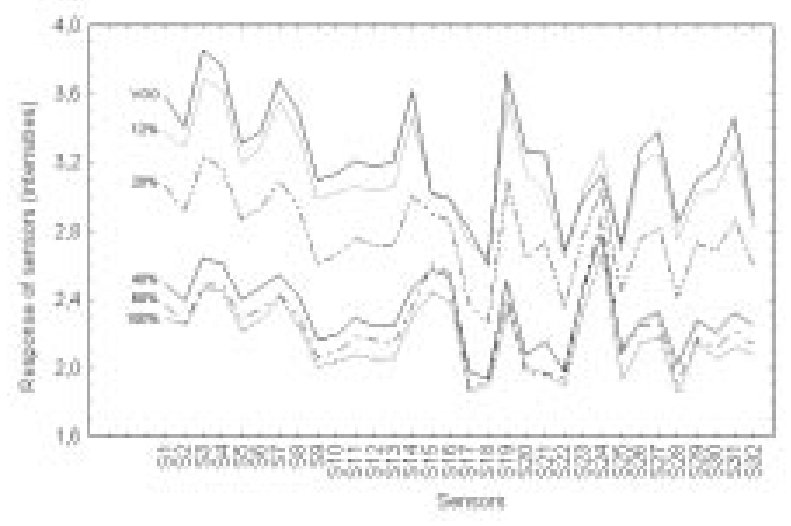

Figure 3

Mean of the raw response of conducting polymer sensors to a pure virgin olive oil and samples spiked with different percentages of a virgin olive oil rancid standard. results (Partridge et al. 1996). The sensors have also other drawbacks as their too long response time (20-40 s), in comparison with MOS (Mielle 1996), and their inherent drift over time or with changes in temperature. The main problem is, however, that they are extremely sensitive to moisture.

Because CPs are sensitive to many types of volatiles, many applications are described in the literature. They are sensitive to alcohols, acetone, benzene and other polar volatile chemicals (Hatfield et al. 1994). References show applications of CPs in foodstuffs like beer and other alcoholic beverages (Pearce et al. 1993; Slater et al. 1993), olive oil (Aparicio et al. 2000), orange juices (Bazemore et al. 1998), fishes (Luzuriaga et al. 1999), milk (Magan et al. 2001). Figure 3 shows the responses of polymer sensors (AromaScan A20S) to virgin olive oils characterised by different levels of oxidation.

Conducting polymers are often associated to other transducer mechanisms as sensing materials. This is the case of the optical sensors based on CPs, since these polymers show spectral changes in the UV-visible region when the doping/dedoping process happens (Kondratowicz et al. 2001). Optical sensors incorporating CPs sensitive to ammonia, humidity, $\mathrm{pH}$ and acetic acid have been recently developed (Kondratowicz et al. 2001; de Marcos et al. 2000). Sensors based on field effect transistor (FET) incorporating a CP as the gate material (Hatfield et al. 2000) or quartz-crystal microbalance associated to CP (Slater et al. 1992) are other examples. Finally, CPs provide a surface to immobilise biological elements like enzymes or antibodies, in order to prepare biosensors. Recently, a dielectric monitoring has been proposed to study the adsorption process of biomolecules onto CPs, such as DNA onto polypyrroles (Saoudi et al. 2000).

\subsection{Acoustic sensors}

Electroacoustic devices based on the piezoelectrical properties of quartz material have been successfully used to implement sensors since 1964 (King 1964). These sensors are based on the propagation of acoustic waves produced by piezoelectrical materials (e.g. quartz or $\mathrm{LiNbO}_{3}$ or $\mathrm{Si}_{-} \mathrm{SiO}_{2}-\mathrm{ZnO}$ ) in a multilayer structure (Lucklum and Hauptmann 2000). Surface acoustic wave (SAW) and bulk acoustic wave (BAW) are the most common of those acoustic sensors. The operation mode of these sensors is based on the physical changes produced on their membranes made of chemically interactive materials (CIM). The physical changes that can be detected are related to the piezoelectric materials used for the acoustic transduction, or the mass density and (visco-)elastic properties of CIM.

The operation principles of SAW and BAW sensors are very similar (D'Amico et al. 1997). However, SAW-type sensor exploits the propagation 
of radiofrequency $\left(10^{2}-10^{3} \mathrm{MHz}\right)$ oscillations (e.g. Rayleigh waves) along a layer consisting at least of a substrate covered by the CIM. The acoustic waves are transmitted by the electrical field generated by electrodes deposited at the surface of the solid. SAW devices produce bi-dimensional waves travelling through the surface of the crystal. Depending on the geometry of the acoustic structure and on the frequency scaling, SAW sensors can produce different types of waves: Rayleigh waves, surface transverse waves, Bleustein-Gulyaev waves, and Lamb and Love waves. The choice of one of these waves or the piezoelectric material $(\mathrm{ZnO}, \mathrm{AIN}$, $\mathrm{Bi}_{12} \mathrm{GeO}_{20}, \alpha-\mathrm{SiO}_{2}, \mathrm{LiTaO}_{3}, \mathrm{LiNbO}_{3}$ ) is influenced by the characteristics of the membrane and by the operation in gaseous or liquid environments. From the sensing point of view, the presence of volatile compounds produces the adsorption of molecules on the sensor and hence changes on the properties of the CIM that affect both the phase velocity and the propagation loss of the acoustic wave. The resulting is a frequency shift whose magnitude is related to the amount of material adsorbed onto the layer sensor.

A BAW sensor is a piezoelectric resonator, often made of quartz, with one or both surfaces covered with a sensitive coating (membrane) of a few $\mu \mathrm{m}$

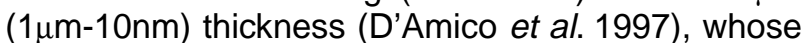
chemical and physical (thermal) characteristics are similar to the gas-chromatography stationary phases. The structure is connected to an amplifier to form an oscillator whose three-dimensional waves travel through the crystal (Schaller et al. 1998) at a frequency of $10-30 \mathrm{MHz}$. In the presence of volatile compounds there is a process of adsorption or absorption of the chemical species that alter the physical properties of the membrane and hence affects the resonant frequency of the structure. The changes are detected by measuring the shift in the resonance frequency; the magnitude of the shift is related to the mass of the compound although the response can be no-linear due to viscoelastic behaviour of the membrane. Because of the response is proportional to the mass adsorbed, this device (a quartz disk sandwiched between two electrodes) is also called quartz crystal microbalance (QMB or QCM) (Ferrari et al. 2000) and it was already proposed as a promising sensor for gas detection in 1964 (King 1964).

Other kinds of acoustic sensors are the flexural plate wave (FPW) sensors and cantilever-based sensors. FPW sensors are similar to SAW sensors although they are coated with a membrane whose thickness is much smaller than the acoustic wavelength (Cai et al. 2000) and, in consequence, the mechanical flexure occurs in the entire membrane. Cantilever-based sensors, which derive from the atomic force microscopy, consist of free-standing cantilever beams coated with a sensor layer that interacts with the analyte (Battiston et al. 2001). The cantilever-based sensor oscillates at a fixed resonance frequency, and any change of the mechanical properties is detected by measuring the shift of the resonance frequency (dynamic mode) or the static deflection (static mode). The mechanism of sensing of microcantilever is similar to SAW and BAW sensors. The molecules are absorbed in the active layer, increasing the mass of the cantilever (Porter et al. 2001). This change of mass loading results in a change of the vibration frequency or amplitude. Thus, the response of a cantilever is characterized by its geometrical dimensions and the vibration frequency among others (Battiston et al. 2001).

Acoustic sensors have various advantages over other sensors, as high sensitivity and short response time, low power consumption and size, and robustness (Gutierrez et al. 2000). The sensitivity of the acoustic sensor is related to the operating frequency (SAW: $100 \mathrm{MHz}-1 \mathrm{GHz}$; BAW: $10-30 \mathrm{MHz}$ ), and it increases as the square of the fundamental frequency does (Ballantine and Wohltjen 1989). Furthermore, the frequency shift is directly proportional to the sensing layer thickness for a specific compound (Li and Ma 2000).

Disadvantages of acoustic sensors are the temperature and humidity dependence, the difficulty of replacing sensors, the poor reproducibility in the deposition of the coating material (Mielle 1996) and certain level of noise (overall in SAW) because of their high frequency (Schaller et al. 1998). In the case of QCM sensors, their main disadvantage is that they need of a thin crystal to increase the sensitivity that prevents their inclusion in multisensor arrays (Ferrari et al. 2000).

The acoustic sensor applications can be divided between physical and chemical applications (Ballantine and Wohltjen 1989). Some physical properties can be measured by acoustic sensors, as temperature, pressure, electric field, displacement and flow (Cai and Grimes 2000). The common characteristic of these sensors is that they have magnetoelastic thick-film as coating material. The chemical applications require two kinds of sensors, liquid-phase sensors and vapour-phase sensors, according to the medium in which they operate (Ballantine and Wohltjen 1989). The vapour-phase acoustic sensors have been used to detect gases and volatiles as $\mathrm{NO}_{2}$ (Müller et al. 2000), $\mathrm{NH}_{3}$ (Ballantine and Wohltjen 1989), xylene, toluene, tetrachloroethylene (Dickert et al. 1999), $\mathrm{H}_{2}$, toxic gases (McGill et al. 2000), organophosphorous compounds (Zimmermann et al. 2001) and $\mathrm{SO}_{2}$ (Qin et al. 2000). Acoustic sensors have also been used to analyse the headspace of foodstuffs as olive oil samples (Di Natale 2001). SAW sensors with a sensitive material containing a high degree of 
hydroxyl groups is used to detect the humidity because it produces changes in the polarity of the coating material (Dickert et al. 1999). Humidity sensors have been manufactured using polymer sensitive to wet air, such as polyimid (Bernou et al. 2000). Although SAW sensors are no suitable to be used in liquid-phase because of their propagation loss inside the liquid interface (Tong and Zhang 1999), some authors have used them to measure the flow of liquid samples (Nomura et al. 2001), or to determine the liquid density and viscosity with a Love-mode acoustic sensor (Herrmann et al. 1999). Finally, SAW sensors are also used in scientific areas as different as biochemistry, electrochemistry (Ballantine and Wohltjen 1989) and immunosensing (Freudenberg et al. 2001).

\subsection{Biosensors}

A biosensor consists of an immobilised biologic molecule (enzymes, cellules or antibodies) next to a transducer, which transforms chemical signal into an electric signal or into other kind of output as optical, acoustic and heat signal when an analyte reaches to it. (Arroyo 1998). Arnold and Meyerhoff (KressRogers 1997) defined biosensors as "a selfcontained analytical device that responds selectively and reversibly to the concentration or activity of chemical species in biological samples". Biosensors then consist of a biological sensing element and a transduction element.

The biological element (Griffiths and Hall 1993) can be made of catalytic (enzymes, microorganisms and tissues) or non-catalytic components (antibodies, receptors and nucleic acids). The characteristics of biological elements allow clustering the biosensors in three great groups: metabolism biosensors (enzymes, combinations of enzymes and cofactors, and cells like algae and bacteria), affinity biosensors (antibodies, "immunosensors") and recombinant biosensors (DNA probes).

The transduction element allows the transformation of the chemical signal, obtained from a biological process, into another kind of signal. According to the kind of the transduced signal, biosensors can also be grouped in electrochemical (amperometric, potentiometric, conductimetric), optical, calorimetric and acoustic biosensors (Griffiths and Hall 1993).

The biosensor sensing mechanisms depend on the transduction technology. In the case of electrochemical biosensors for example, the transduction system is based on an electrochemical nature process, and so the transduced signal is electric. Most of the commercial biosensors are electrochemical; amperometric biosensors being the most widespread because the electrochemical instrumentation is relatively simple and inexpensive. The current flows at constant potential with respect to a reference electrode in the amperometric sensors, and the current generated by the oxidation or reduction of electroactive species at the surface of the working electrode is measured (Griffiths and Hall 1993). In amperometric biosensors, redox enzymes (oxidoreductases) have a special importance, since the transformation of the substrate takes place with a transfer of electron between redox enzymes and electrodes. These redox enzymes are oxidases, peroxidases and dehydrogenases (Reviejo and Pingarrón 2000). There are four main categories of amperometric sensors (Palleschi and Cubadda 2001): Oxygen electrodes, hydrogen peroxide electrodes, carbon-base mediated electrodes and NADH electrochemical sensors.

The potentiometric biosensors measure the changes of potential at constant current (usually zero). Three kinds of transducer are used in the potentiometric biosensors: ion selective electrodes (ISEs), gas sensing electrodes, and field effect transistors (FETs) (Griffiths and Hall 1993).

In the case of conductimetric biosensors changes of conductivity between two electrodes are measured. This kind of transduction technology is not widely used due to low selectivity.

Nowadays, lots of studies have been done to fabricate electron-transferring interfaces between redox enzymes and electrodes in order to perform an enhanced electrochemical biosensor (Shinohara et al. 2000). These mediators are able to replace oxygen as an electron acceptor and to operate at a potential that greatly reduces the effects of other electrochemically active species (White and Turner 1997). Some of these mediators are ferrocene and its derivatives, cobaltphtalocyanine, tetrathiafulvalene, electropolymers (Albareda-Sirvent 2000), and proteins (Shinohara et al. 2000).

Optical biosensors are based on optical changes while the biochemical reaction takes place. If a light beam is propagated through a waveguide, then the internally reflected light generates an electromagnetic "evanescent wave" that can be used to excite fluorescent molecules at the surface of the waveguide. The "evanescent wave" can couple with the electron plasma of a metal when the waveguide is coated with a metal thin layer. It causes the electrons to oscillate and thus generating a surface plasmon wave (Griffiths and Hall 1993) that is characterised by high sensitivity and specificity. The surface plasmon is an electromagnetic wave associated with the longitudinal oscillation of the free electron gas on the interface of the metal and the dielectric (Caide and Sui 2000). Recently, surface plasmon resonance interferometry (SPRI) has been established as a novel method (Nikitin et al. 2000) that gains in sensitivity and resolution for the detection of a multiplicity of analytes.

Finally, there are calorimetric and acoustic biosensors. The calorimetric biosensors are based 
Table III

Methods for immobilising the enzymes of biosensors

\begin{tabular}{|c|c|c|}
\hline Method for enzyme immobilisation & Brief description & References \\
\hline Entrapment & Immobilisation in matrices like gels, polymers or pastes. & Ortega et al. 1998 \\
\hline Microencapsulation & $\begin{array}{l}\text { The enzymes are enclosed within semipermeable } \\
\text { polymer membranes. }\end{array}$ & Ramos et al. 2001 \\
\hline Physical adsorption & $\begin{array}{l}\text { van der Waals attraction forces between an enzyme } \\
\text { and a solid support surface. }\end{array}$ & Lüth et al. 2000 \\
\hline Covalent binding & Enzymes and carriers are bound by covalent bond. & Senillou et al. 1999 \\
\hline Cross-linking & $\begin{array}{l}\text { Formation of three-dimensional linkings between } \\
\text { the biological material and bi- or } \\
\text { multifunctional reagents. }\end{array}$ & Dzyadevych et al. 2001 \\
\hline
\end{tabular}

on the fact that almost all biochemical reactions are exothermic. Their commercial success is very limited to the date, thermopiles and enzyme thermistors being the most used. The acoustic biosensors measure changes in the acoustic properties of the sensors. There are two types: surface acoustic wave or bulk wave (Griffiths and Hall 1993).

The principal advantage of enzyme biosensors is related with their high specificity (stereoselectivity and regiospecificity) and catalytic activity. However, they have the disadvantages of low stability and possibility of being reusable (Arroyo 1998). These inconveniences can be partially avoided by the immobilisation of the enzymes, which consists of fixing enzymes onto a surface by physical or chemical methods in order to obtain an insoluble by-product with catalytic activity. The immobilisation provides advantageous effects over enzymes such as an activity increment, high reusability and feasibility of handling and control. But the enzyme biosensors also have inherent disadvantages such as heterogeneity of the system, high cost, and changes in the conformation of the enzymes (Arroyo 1998). The conventional methods of the enzyme immobilisation include covalent binding, encapsulation in a polymer or cross-linking to a suitable supporting matrix (Lillis et al. 2000). Table III shows different methods to immobilise the enzymes.

The applications of biosensors spread over a lot of fields like clinical, agriculture, military, industrial and food areas although their commercial set up is being carried out slowly. In medicine, biosensors are used in the assessment of drug or biomolecule concentrations in blood, serum or other corporal fluid in-vivo or in-vitro measurements, and data are used in diagnostic or on-line monitoring (Liu and Li 2000). The agricultural applications of biosensors are focused on the detection of viral, bacteria and fungal infections, the use of fertilizers and pesticides (Griffiths and Hall 1993), and volatiles released by damaged plants in glasshouses (Schütz et al. 2000).
In military defence, biosensors could be used to detect nerve gases and other products used in chemical warfare (Griffiths and Hall 1993). Biosensors are applied to the control processes in pharmaceutical, chemical and petroleum industries, mining and construction (Griffiths and Hall 1993). The environmental control of toxic compounds and pollutant gases (Köhler et al. 2000) and wastewater toxicity (Liao et al. 2001) can also be done by biosensors. Finally, biosensors have been also used in Food Technology to monitor the quality control of raw materials and on-line or off-line manufacturing processes. Thus, glucose and sucrose biosensors have been used to control the process of alcohol fermentation (Ferreira et al. 2001), and to detect enterotoxins (Tempelman et al. 1996) and bacteria (Su et al. 2001) in many foodstuffs. Recently, a biosensor based on catalase enzyme has been developed for hydroperoxide determination in extra virgin olive oil samples (Campanella et al. 2001).

\section{THE ELECTRONIC NOSE}

Recently, sensors with sensitivity to a wide range of volatiles compounds have been integrated in a system called electronic nose. The name of 'electronic nose' is due to the similarities between this instrument and the physiological system. Gardner and Bartlett (1994) defined electronic nose as an instrument, which comprises an array of electronic chemical sensors with partial specificity and an appropriate pattern-recognition system, capable of recognising simple or complex odours. Using this definition it can be though that electronic noses are composed of parts such as arrays of non-specific solid state gas sensor, a variety of transducers, data collectors and data analysis tools, all oriented to the classification and quantification of chemical clusters of volatile compounds, including, in particular, odours (D'Amico et al. 2000). Nevertheless, the term "electronic nose" is being incorrectly used to 
name different systems, as mass-spectra based system. Other authors use "sensor array technology" (Mielle 2000), "electronic olfactometry" (García et al. 2001), "active odour sensing system" (Nakamoto et al. 2001) and "artificial olfaction system" (Di Natale et al. 2000), between other synonyms, to refer to a gas sensor system.

When an analysis is carried out with an electronic nose, the issues that should be taken into account are: the sampling method, the sensor array and the sensor cleaning. The first of them is the sampling method. Previously, the sample is put in a sample chamber at a controlled temperature. In the odour analysis, the headspace is analysed rather than the sample itself. There are two methods for sampling the headspace of the material to be analysed: static headspace analysis and dynamic headspace analysis. Static headspace consists of analysing an aliquot from the vapour phase, in equilibrium with the sample, in a sealed vial subjected to a determined temperature over certain time. The so-called headspace generation time allows a generation of volatile compounds until a constant concentration of them in the headspace. The volatile compounds are transferred into the sensor chamber once the equilibrium between vapour and liquid/solid phase is reached.

Dynamic headspace, on the contrary, consists of sweeping the volatile compounds of the sample, subjected to a determined temperature, with an inert gas at a controlled flow and passing them through the sensor chamber. In liquid samples, stirring the sample or bubbling an inert gas through the sample usually increases the generation of volatile compounds.

Many variables affect the sampling method, such as the temperature, the surface area of the sample, and the volume of the headspace (Hodgins 1997). Furthermore, the concentration of a volatile compound in the liquid/solid sample and its partial pressure are decisive in the concentration of the same volatile compound in the vapour phase (Mielle 1996). Schaak et al. (1999) carried out a study of the correlation between metal-oxide sensor response and the vapour pressure of pure chemical compounds. Other variables are the humidity and temperature of the carrier gas used in the sampling process. Both factors affect the sensor signal, so that they must be precisely controlled. On the other hand, the material of vessels and tubes should be inert as glass, stainless steel, and PTFE (Hodgins 1997).

After the sampling method, the volatile compounds are located in the sensor chamber where the sensor array is placed. The sensor array can be constituted by cold, hot sensors or both kinds of sensors (Lucas et al. 1998). Sensors usually have a poor selectivity, for instance metal oxide gas sensors (Mielle 1996). The aim of combining sensors

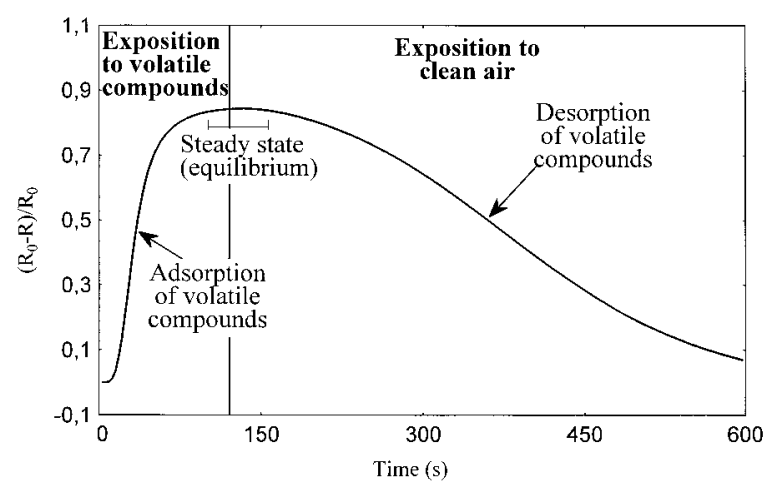

Figure 4

Typical response of a MOS sensor (Alpha MOS 4000). Previously, data were preprocessed using the fractional difference equation.

with a slight change in selectivity is to provide an overall pattern or "fingerprint" as a single response, which is characteristic of the odour. The power of discrimination of a sensing system increases with the number of sensors in the sensor array (Shurmer and Gardner 1992), since each sensor provides information about a broad profile of compounds. However, a large number of sensors can provide useless redundant information and noise. Furthermore, data from an array composed by sensors with different chemical principles are more effective than those provided by sensors with the same principle (Stetter et al. 2000).

The interaction between the volatile compounds and the sensitive sensor surface provides physical/chemical changes in the sensor. These changes result in an electrical measurable signal that is recorded along the measuring time. The typical response of sensors (e.g., MOS and CP sensors) (Figure 4) consists of an initial slope related to an adsorption process of volatiles onto the sensor surface. After a while, a dynamic equilibrium is reached and the volatiles are adsorbed and desorbed at the same speed (Schaller et al. 1998). At this stage, the sensor signal is constant. Finally, the volatile desorption occurs and the sensor signal shows a negative slight slope; the sensor tends to recover its initial value.

After the measuring time, the sensors must be cleaned to get the baseline again and avoid the cross-contamination between samples. The cleaning method depends on the kind of sensor. In the case of conducting polymers a clean air, previously passed over a $2 \%$ water/butanol solution, can be blown over the sensor array (Aparicio et al. 2000). In metal-oxide sensors clean carrier gas is blown continually over the sensor during the non-measuring time (González Martín et al. 1999; Bazzo et al. 1999), since a dynamic cleaning provides a faster recovery of the baseline (Bazzo et al. 1999). 
The sensor responses depend on many variables (Gardner and Bartlett 1994): the flow of the carrier gas, the nature of the odour, interaction kinetics, the sensing material (nature and substrate), the odour diffusion within the sensing material, and the ambient conditions (temperature, humidity, pressure, etc).

During the analysis, the odour sensing system should have an electronic control of sensor temperature, valves, sample temperature, frequency of the acoustic sensors, etc. Furthermore, data from sensor responses must be digitised and acquired in a PC. After the analysis, data are pre-processed and included in a multivariate data analysis.

Although electronic noses are useful for rapid on-line screening, many inconveniences need to be overcome before. The main limitations of an e-nose are related to drift, noise, repeatability, environmental influence (sensitivity to temperature and humidity), poisoning and non-linearity in sensor response (Craven et al. 1996). Many studies are being carried out to enhance the performance of the electronic nose. The improvements of the electronic nose can be focused on the sampling system, new sensing materials and transducers combining different sensors, and multivariate statistical procedures (Stetter et al. 2000; Göpel 2000; Craven et al. 1996). Recently, the electronic nose has been coupled with other techniques. The coupling of gas chromatography (GC) with a sensor system has been proposed (Kohl et al. 2000; Masila et al. 1999). This coupling shows an improvement in reproducibility. Sensor arrays have also been coupled with a thermal desorption unit, with a tenax trap (Muenchmeyer et al. 2000) or with

Table IV

Main applications of the Electronic nose in Food Science

\begin{tabular}{ll}
\hline \multicolumn{1}{c}{ Foodstuffs } & \multicolumn{1}{c}{ References } \\
\hline Beer & Shurmer and Gardner, 1992; Wilson \\
& et al. 2000; Pearce et al. 1993 \\
Wine & Guadarrama et al. 2001; Di Natale et al. 2000 \\
Meat products & Braggins et al. 1999; Vernat-Rossi 1996 \\
Fish & Luzuriaga and Balaban 1999 \\
Fruit & Winquist et al. 1990; Bazemore et al. 1997; \\
& Hines et al. 1999; Sinesio et al. 2000 \\
Coffee & Aishima, 1991; Singh et al. 1996; Gardner \\
Tea & et al. 1992; Pardo et al. 2000b \\
Olive oil & Lucas et al. 1998 \\
Fat & Aparicio et al. 2000; Stella et al. 2000; \\
Milk & Pardo et al. 2000a \\
Cereals & Carrapiso et al. 2001; Muhl et al. 2000 \\
Chocolate & Magan et al. 2001; Zondervan et al. 1999 \\
& Philip et al. 2000; Schnürer et al. 1999 \\
\hline
\end{tabular}

solid-phase microextraction (SPME) technique (Guadarrama et al. 2001).

The commercial electronic noses have allowed the development of new applications of this kind of system. There are many applications related to toxic gases, environment and medicine. However, the main applications are found in food industry. The applications in foodstuff include quality assessment (Sinesio et al. 2000), control of manufacturing process (Zondervan et al. 1999), checking the aroma changes during the storage (Luzuriaga and Balaban 1999), and study of packaging materials (Werlein 2001). Table IV summarises applications of the electronic nose in Food Science.

\section{THE ELECTRONIC TONGUE}

Recently, the same concept of artificial sense applied to electronic nose has been applied to the sense of taste. So, new taste sensors have been developed to be integrated in an 'electronic tongue'. D'Amico et al. (2000) defined electronic tongues as instruments that include arrays of non-specific solid state ion sensors, transducers even of different types, data collectors and data analysis tools, all oriented to the classification of liquid samples and the quantification of chemical species presented into them.

The scheme of the system is very similar to that of the electronic nose, except the conditioning of the sample and the measurement (D'Amico et al. 2000). Moreover, the transducer mechanisms of the taste sensors are different. Winquist et al. (1999) used an electronic tongue based on pulsed voltammetry. These authors used metallic sensors that are affected by an onset of a voltage pulse. Authors measured the current transients and obtained a voltammogram based on large amplitude pulsed voltammetry (LAPV). On the other hand, Toko (2000) manufactured taste sensors that consisted of polymer/lipid membranes and $\mathrm{Ag} / \mathrm{AgCl}$ electrodes that produce electrical signals in response to taste substances.

Many applications of the electronic tongue have been suggested. Electronic tongue has been applied in tea (Ivarsson et al. 2001), soy sauce (liyama et al. 2000), wine and mineral water (Legin et al. 2000) between others. Besides, the combination of electronic nose and electronic tongue data provides an improvement in the classification rate (Winquist et al. 1999; Rong et al. 2000).

\section{DATA ANALYSIS}

The quantity and complexity of the data collected by an electronic nose do not allow the use of conventional data analysis. The electronic nose produces a tri-dimensional $(n, k, t)$ output matrix, 
Table V

Equations suggested for the normalization of the sensor baselines

\begin{tabular}{ll}
\hline \multicolumn{1}{c}{ Normalization } & \multicolumn{1}{c}{ Equation } \\
\hline Difference & $\mathrm{X}=\mathrm{R}-\mathrm{R}_{0}$ \\
Relative & $\mathrm{X}=\mathrm{R} / \mathrm{R}_{0}$ \\
Fractional difference & $\mathrm{X}=\left(\mathrm{R}-\mathrm{R}_{0}\right) / \mathrm{R}_{0}$ or $\mathrm{X}=\left(\mathrm{R}_{0}-\mathrm{R}\right) / \mathrm{R}_{0}$ \\
Logarithm & $\mathrm{X}=\log \left(\mathrm{R}-\mathrm{R}_{0}\right)$ \\
\hline
\end{tabular}

where " $n$ " is the number of samples, " $k$ " is the number of sensors and " $\mathrm{t}$ " is the number of points supplied by each sensor. Such an amount of information requires a data pre-processing step to remove redundant and irrelevant information but retaining the original information as much as possible.

\subsection{Pre-processing data analysis}

Gutiérrez-Osuna and Nagle (1999) suggest three steps for the data pre-processing: baseline manipulation, compression of data and normalization, although the order of these operations is variable. The baseline manipulation is a transformation based on the initial value of the sensors; Table $V$ shows the most common transformations.

Data compression is necessary to obtain a matrix with a reasonable size; for example, a typical electronic nose (18 sensors, a sampling frequency of $0.5 \mathrm{~s}$ and sampling time of $600 \mathrm{~s}$ ) will produce 21600 data per sample. Data compression consists in selecting the regions of the sensor response with the most differential properties without removing the essential information. There are many algorithms for extracting the information from the time dependant sensor response. Hermle et al. (1999) have

Table VI

The most applied algorithms to the data compression

\begin{tabular}{ll}
\hline \multicolumn{1}{c}{ Model } & \multicolumn{1}{c}{ Description/equation } \\
\hline Steady-state or maximum $^{1,2,3,4}$ & $\mathrm{Y}=\mathrm{R}(\mathrm{tmax})$, maximum response \\
Transient integral $^{1,4}$ & $\mathrm{Y}=\Sigma \mathrm{R}(\mathrm{t}) \Delta \mathrm{t}$ \\
Windowed Time Slicing $^{1,}$ & $\left.\mathrm{~W}=\Sigma \mathrm{R}(\mathrm{t}) \Delta \mathrm{tK}(\mathrm{t}) \Delta \mathrm{t} ; \mathrm{K}(\mathrm{t})=1 /(1+(\mathrm{t}-\mathrm{c}) / \mathrm{a})^{2 \mathrm{~b}}\right)$ \\
Window averaging $^{5}$ & The average of the neighbour 100 data. \\
Response Time $^{5}$ & $\mathrm{~A}$ datum per time step. \\
Maximum derivation $^{2,3,4}$ & $\mathrm{Y}=\operatorname{Max}\left(\mathrm{R}^{\prime}(\mathrm{t})\right)$ \\
Time for the signal to reach its maximum $^{2}$ & $\mathrm{Y}=\operatorname{Max}\{\mathrm{t} / \mathrm{R}(\mathrm{t})=\operatorname{Max}\}$ \\
Time for the signal to reach $75 \%$ of the full response $^{6}$ & $\mathrm{Y}=\operatorname{Max}\{\mathrm{t} / \mathrm{R}(\mathrm{t})=0.75 \mathrm{Max}\}$ \\
Area below the signal $^{2}$ & $\mathrm{Y}=\operatorname{Sum}(\mathrm{R}-\mathrm{R} 0)$ \\
\hline
\end{tabular}

${ }^{1}$ Gutiérrez-Osuna and Nagle 1999; ${ }^{2}$ Hermle et al. 1999; ${ }^{3}$ Pardo et al. 2000a; ${ }^{4}$ Paulsson et al. 2000; 5 Wilson et al. 2000; 6 Brown et al. 2000;.

Table VII

Methods for the data normalization

\begin{tabular}{|c|c|}
\hline Method & Description \\
\hline Vector normalization $^{a, b, c}$ & $\mathrm{Y}=\mathrm{R} /\left(\Sigma \mathrm{R}^{2}\right)^{1 / 2}$ \\
\hline Vector auto-scaling ${ }^{\mathrm{a}, \mathrm{c}}$ & $Y=(R-\bar{R}) / \delta_{R} ;$ mean $(\bar{R})$ \& standard deviation $\left(\delta_{R}\right)$ per sample. \\
\hline Dimension auto-scaling ${ }^{\mathrm{a}, \mathrm{c}}$ & $Y=(R-\bar{R}) / \delta_{R} ;$ mean $(\bar{R})$ \& standard deviation $\left(\delta_{R}\right)$ per dimension. \\
\hline Sensor normalization ${ }^{c}$ & $\mathrm{Y}=\left(\mathrm{R}-\mathrm{R}^{\mathrm{min}}\right) /\left(\mathrm{R}^{\mathrm{max}}-\mathrm{R}^{\mathrm{min}}\right)$ \\
\hline Maximum normalization ${ }^{d}$ & $\mathrm{Y}=\mathrm{R} / \mathrm{Max}(\mathrm{R})$ \\
\hline Sum normalization $^{d}$ & $Y=R / \Sigma R$ \\
\hline
\end{tabular}

a Gutierrez-Osuna and Nagle, 1999; b Romain et al. 2000; c Gardner et al. 1998; d Amine et al. 1999. 
evaluated 22 methods to reduce the number of data that are grouped into three classes: methods that consider the extremes values, methods that consider the transient behaviour, and methods that consider the shape of the signal. Table VI summarises the models used by various authors although many commercial electronic noses use only a single data per sensor such as the steady state or its maximum.

Data normalization is the third step. The scaling (also so-called standardization) is able to readjust the values of the sensor responses to an equal basis, avoiding that some variables weight more than others in the results. For instance, the vector auto- scaling normalization or the sample wise normalization normalizes the dimensions of each sample to mean zero, and standard deviation 1. Normalization methods are able to avoid experimental variation, and to reduce the computational errors when a pattern recognition technique is applied (Gardner and Bartlett 1994). Table VII shows some normalization methods.

Data pre-processing techniques can be evaluated by setting a score based on the prediction of the classification of a training set of samples. Combinations of feature extractions can be used, but only the best parameters should be selected. This selection can be performed using principal components analysis (Pardo et al. 2000b; Wilson et al. 2000; Amine et al. 1999), linear discriminant analysis (Gutierrez-Osuna and Nagle 1999) or neural network (Gardner et al. 1998) for evaluating the results. Thus, Wilson et al. (2000) found differences in the discrimination studies applying the fractional difference method (baseline) and raw data as input versus different time steps, but they did not found significant differences between the temporal filtering methods. We have however found that the fractional difference method (baseline) and the window averaging (data compression) are the best for clustering and classification applications.

\subsection{Multivariate data analysis}

Multivariate statistical procedures can be applied to pre-processed and normalized sensor responses, since it is able to perform simultaneous analyses of numerous variables. These procedures can be clustered into descriptive and explanatory analysis, although chemometricians prefer the terms nonsupervised and supervised (Aparicio 2000). The non-supervised procedures are characterized by non-having previous hypothesis classifying the samples while the supervised procedures have the objective of checking a previous hypothesis. The procedures can also be classified as parametric and nonparametric, or linear and non-linear. The first group concerns to the probability distribution of variables, and the non-parametric procedures are suggested when the sample sizes are small (Statistica 2000). The non-linear relation between the response matrix and the compound concentration makes the non-linear procedures attractive for sensor analyses.

The most applied multivariate procedures are cluster analysis, factorial analysis, multidimensional scaling, discriminant analysis, regression analysis and artificial neural networks. Figure 5 shows an analysis with a sensor array using multivariate statistical analysis.

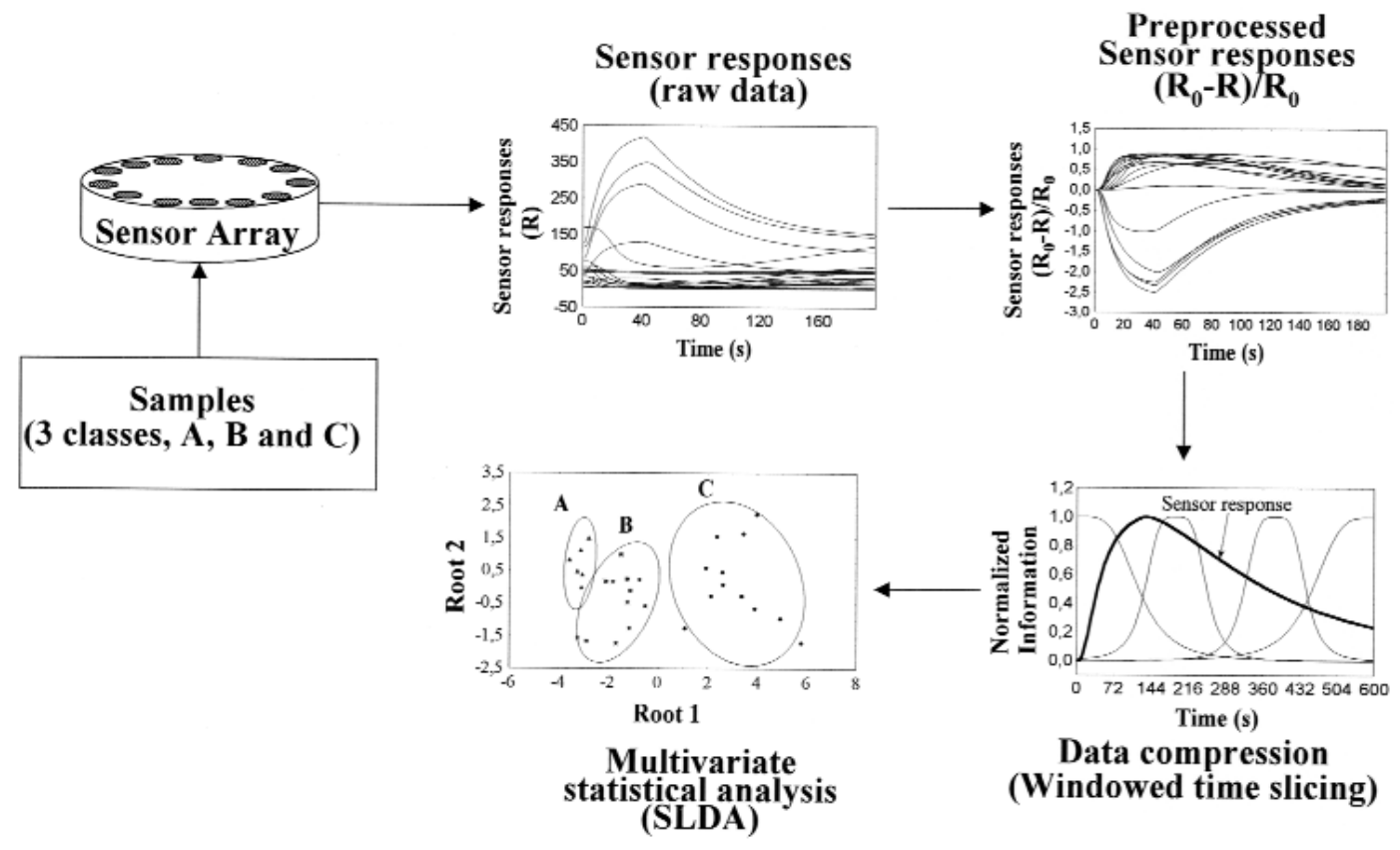

Figure 5

Scheme of the process to analyse the information of a sensor array. 


\subsubsection{Cluster Analysis}

Cluster analysis is a generic name used to call the methods designed to understand the information of data matrices, to describe the similarities and dissimilarities between objects, and to single out categories grouping similar objects. The different types of cluster analysis are: K-means clustering, block clustering and tree clustering (Aparicio 2000). Aishima (1991) used the cluster analysis to classify four types of coffee while Pearce et al. (1993) used it to distinguish two kinds of lagers. Cluster analysis has also been used to study the similarities between sensors in order to select the sensors with the highest sensitivity from each batch of sensors and so avoiding redundancy (Chaudry et al. 2000; Penza et al. 2000).

\subsubsection{Factorial Analysis}

This kind of analysis consists in obtaining unobservable factors from the data matrix in order to get a smaller matrix but retaining most of the original information (percentage of the variance explained). Principal component analysis (PCA) is one of the most known factorial analysis. It is easy to interpret and it is not necessary to invert the matrix when carrying out this analysis. PCA has been used (Capone et al. 2000) to remove the variable redundancy, to detect the outliers (Amine et al. 1999), and as pre-treatment of data previously to use neural network (Pardo et al. 2000a).

\subsubsection{Discriminant Analysis}

This supervised procedure allows classifying samples into pre-established groups. The procedure selects the independent variables (sensor responses) that better classify the samples. Stepwise linear discriminant analysis (SLDA) or discriminant function analysis (DFA) are the most used. Thus, DFA has been applied by Gardner et al. (1992) to classify coffee aromas while Aparicio et al. (2000) applied SLDA to classify olive oil samples by the data obtained with conducting polymers.

\subsubsection{Regression analysis}

Multiple regression is one of the most applied regression methods. The general purpose of the multiple regression is to study the relationship between several independent or predictor variable (e.g., pre-processed sensor data) and a dependent or criterion variable (e.g., the known concentrations of a chemical compound or the scores of a foodstuff obtained by a panel test). The redundancy, the multicollinearity and the assumption of linearity of the sensor responses are the main problems of the regression models, and they should be taken into account before applying regression procedures. The non-linear property of sensors, for example, is due to the saturation during the adsorption process, the inhibition or competition between gas species, and the hysteresis or ageing of the sensors (Kato et al. 2000).

Partial Least squares (PLS), Multiple linear regression (MLR), principal component regression (PCR) and ridge regression (RR) are among the most used regression procedures. Edible oils have been analysed by PLS and MLR (Amine et al. 1999), PLS showing the best results. PCR and RR have also been applied to correlate the sensor responses to the percentages of rancidity in virgin olive oils (Aparicio et al. 2000).

\subsection{Artificial neural networks}

Artificial neural networks (ANNs) have been used to analyse high complex and non-linear data with satisfactory results. ANNs are useful analytical methods with advantageous properties as adaptability (learning, self-organisation, generalisation and training) and noise tolerance (Gardner et al. 1990) that make them appropriate for e-nose applications. Furthermore, ANNs have the ability to handle non-linear data and to compensate for the drift of the sensor array (Lazzerini and Maggiore 1998). ANNs have, however, some disadvantages as the subjectivity on the choice of the way in which the inputs are pre-processed and the difficulty in selecting an optimum architecture and training procedure (Singh et al. 1996). Another drawback is that it is difficult to gain insight into the knowledge that ANN analysis holds. Besides, the parameters at the beginning of the analysis are usually set to random initial values, since no physical meaning can be associated with them (Lazzerini and Maggiore 1998) with the negative consequence of an unpredictable training time to achieve the optimal result. Thus, previous mathematical analyses can help to get a good knowledge of the data. In fact, principal components of a PCA can be used as inputs of the neural network model. On the other

Table VIII

\section{Applications of artificial neural networks}

\begin{tabular}{|c|c|}
\hline ANN method & References \\
\hline Multilayer perceptron (MLP) & $\begin{array}{l}\text { Pardo et al. 2000c; Gardner et al. 1998; } \\
\text { Wilson et al. } 2000\end{array}$ \\
\hline Radial basis function (RBF) & Evans et al. 2000; Wilson et al. 2000 \\
\hline Probabilistic neural networks (PNN) & McGill et al. 2000 \\
\hline Backpropagation neural networks & $\begin{array}{l}\text { Magan et al. 2001; Haugen et al. 1997; } \\
\text { Romain et al. 1997; Tao and Seals 1993; } \\
\text { Dickert et al. 1999; Zondervan et al. } 1999\end{array}$ \\
\hline Feed-forward networks & $\begin{array}{l}\text { Paulsson et al. 2000; Reibel et al. 2000; } \\
\text { Qin and Wu 2001; Schweizer-Berberich et al. } 2000\end{array}$ \\
\hline Self organizing map (SOM) & Ortega et al. 2000; Sinesio et al. 2000 \\
\hline
\end{tabular}


hand, ANN needs, like the human brain, a previous training stage with a known data set in order to reduce the error of the model. The training process allows determining the accuracy of the model, but a re-training process should be applied periodically when a change is done in the system, such as the replacement of the set of sensors (Hodings 1997). Some neural network applications in electronic nose and sensor array are showed in Table VIII.

The prediction and discrimination of odours can also be done with exact mathematical procedures, but always there is inexactness as part of the original model, which escapes of the mathematical model. Thus, fuzzy logic has been integrated in neural network models in order to join the advantages of both methods. Singh et al. (1996) carried out a comparative study of fuzzy neural networks and back-propagation neural networks, the former showing the best performance. Fuzzy logic can be introduced in neural networks by different ways, so there are many kinds of fuzzy neural networks (FNNs). For instance, data can be fuzzified and be used as inputs in ANN. Other authors have applied a linguistic fuzzy model to classify signals produced by a sensor array (Lazzerini and Maggiore 1998). Hong (1999) also applied fuzzy logic to compensate the non-linear bias drift of sensors.

\section{REFERENCES}

Aishima, T. (1991). Aroma discrimination by pattern recognition analysis of responses from semiconductor gas sensor array. J. Agric. Food Chem., 39, 752-756.

Albareda-Sirvent, M., Merkoci, A., Alegret, S. (2000). Configurations used in the design of screen-printed enzymatic biosensors. A review. Sens. Actuators B, 69, 153-163.

Amine, H., Bazzo, S., Labreche, S. (1999). Intensity and quality discrimination using the Fox4000 gas sensor array system In: Electronic Noses \& Sensor Array Based System, Design and Applications, p. 235-248. W.J. Hurst (Ed.), Technomic Co., Inc., Lancaster, PA.

Angerosa, F. (2000). Sensory quality of olive oils. In: Handbook of Olive Oil: Analysis and Properties, p. 355-392. J. Harwood and R. Aparicio (Eds.), Aspen:Gaithersburg, MA.

Aparicio, R. (2000). Characterization: Mathematical procedures for chemical analysis In: Handbook of Olive Oil. Analysis and Properties, p. 285-353. J. Harwood and R. Aparicio (Eds.), Aspen: Gaithersburg, MA.

Aparicio, R., Alonso, M.V., Morales, M.T., Calvente J.J. (1994). Relationship between COI Test and other sensory profiles by statistical procedures. Grasas Aceites 45, 26-41.

Aparicio, R., Morales, M.T., Alonso, M.V. (1996). Relationship between volatile compounds and sensory attributes by statistical sensory wheel. J. Am. Oil Chem. Soc. 73, 1253-1264.

Aparicio, R., Rocha, S.M., Delgadillo, I., Morales, M.T. (2000). Detection of rancid defect virgin olive oil by electronic nose. J. Agri. Food Chem., 48, 3, 855-860.

Arroyo, M. (1998). Inmobilized enzymes: Theory, methods of study and applications. Ars Pharmaceutica, 39, 2, 23-39.
Ballantine, D.S., Wohltjen, H. (1989). Surface acoustic wave. Devices for chemical analysis. Anal. Chem., 61, 11, 704-715.

Battiston, F.M., Ramseyer, J.-P., Lang, H.P., Baller, M.K., Gerber, Ch., Gimzewski, J.K., Meyer, E., Güntherodt, H.-J. (2001). A chemical sensor based on a microfabricated cantilever array with simultaneous resonance-frequency and bending readout. Sens. Actuators B, 77, 122-131.

Bazemore, R., Rouseff, R. (1998). Discrimination of thermally treated orange juices by an electronic nose equipped with organic polymer sensors. Semin. Food Anal., 3, 59-66.

Bazemore, R., Rouseff, R., Nordby, H., Goodner, K., Jella, P. (1997). Discrimination of grapefruit juice varietal differences by an electronic nose equipped with metal oxide sensors. Semin. Food Anal., 2, 239-246.

Bazzo, S., Loubet, F., Labreche, S., Tan, T.T. (1999). Optimization of Fox sensor array system for QC packaging in factory environment. Robustness, sample throughput and transferability In: Electronic Noses \& Sensor Array Based System, Design and Applications, p. 225-234. W.J. Hurst (Ed.), Technomic Co, Inc., Lancaster, PA.

Bazzo, S., Loubet, F., Tan, T.T., Hewitt-Jones, J.D., Engelen-Cornax, C.E.M., Quadt, J.F.A. (1998). Quality control of edible oils using an electronic nose. Semin. Food Anal., 3, 15-25.

Bernou, C., Rebière, D., Pistré, J. (2000). Microwave sensors: a new sensing principle. Application to humidity detection. Sens. Actuators B, 68, 88-93.

Braggins, T.J., Frost, D.A., Agnew, M.P., Farouk, M.M. (1999). Evaluation of an electronic nose for use in the meat industry. In: Electronic Noses \& Sensor Array Based System, Design and Applications, p. 51-82. W.J. Hurst (Ed.), Technomic Publishing:Lancaster, PA.

Breer, H. (1997). Sense of smell: Signal recognition and transduction in olfactory receptor neurons In: Handbook of Biosensors and Electronic Noses. Medicine, Food and Environment, p. 521-532. E. Kress-Rogers (Ed). CRC Press: Boca Raton, FL.

Brown, J.R., Haycock, P.W., Smith, L.M., Jones, A.C., Williams, E.W. (2000). Response behaviour of tin oxide thin film gas sensors grown by MOCVD. Sens. Actuators B, 63, 109-114.

Cai, Q.Y., Grimes, C.A. (2000). A remote query magnetoelastic $\mathrm{pH}$ sensor. Sens. Actuators $B, 71$, 112-117.

Cai, Q.Y., Park, J., Heldsinger, D., Hsieh, M.D., Zellers, E.T. (2000). Vapor recognition with an integrated array of polymer-coated flexural plate wave sensors. Sens. Actuators B, 62, 121-130.

Caide, X., Sui, S F. (2000). Characterization of surface plasmon resonance biosensor. Sens. Actuators B, 66, 174-177.

Campanella, L., Sammartino, M.P., Tomasseti, M., Zannella, S. (2001). Hydroperoxide determination by a catalase OPPE: Application to the study of extra virgin olive oil rancidification process. Sens. Actuators B, 76, 158-165.

Campos, M., Bulhoes, L.O.S., Lindino, C.A. (2000). Gas-sensitive characteristics of metal/semiconductor polymer Schottky device. Sens. Actuators A, 87, 67-71.

Capone, S., Siciliano, P., Quaranta, F., Rella, R., Epifani, M., Vasanelli, L. (2000). Analysis of vapours and foods by means of an electronic nose based on a sol-gel metal oxide sensors array. Sens. Actuators B, 69, 230-235. 
Chaudry, A.N., Hawkins, T.M., Travers, P.J. (2000). A method for selecting an optimum sensor array. Sens. Actuators B, 69, 236-242.

Comini, E, Faglia, G., Sberveglieri, G., Li, Y.X., Wlodarski, W., Ghantasala, M.K. (2000). Sensitivity enhancement towards ethanol and methanol of $\mathrm{TiO} 2$ films doped with $\mathrm{Pt}$ and $\mathrm{Nb}$, Sens. Actuators B, 64, 169-174.

Craven, M.A., Gardner, J.W., Bartlett, P.N. (1996). Electronic noses-development and future prospects. Trends in Anal. Chem., 15, 9, 486-493.

D'Amico, A., Di Natale, C., Paolesse, R. (2000). Portraits of gases and liquids by arrays of non-specific chemical sensors: trends and perspectives. Sens. Actuators B, 68, 324-330.

D'Amico, A., Di Natale, C., Verona, E. (1997). Acoustic devices. In: Handbook of Biosensors and Electronic Noses. Medicine, Food and Environment, p. 197-223. E. Kress-Rogers (Ed). CRC Press: Boca Raton, FL.

De Marcos, S., Asensio, C., Uruñuela, I., Gallarta, F., Galbán, J., Castillo, J.R. (2000). New approaches to polyaniline optical sensors: $\mathrm{pH}$, acetic acid and amonia determination. Química Analítica, 19, 1, 99-104.

Di Natale, C., Macagnano, A., Nardis, S., Paolesse, R., Falconi, C., Proietti, E., Siciliano, P., Rella, R., Taurino, A., D'Amico, A. (2001). Comparison and integration of arrays of quartz resonators and metal-oxide semiconductor chemoresistors in the quality evaluation of olive oil. Sens. Actuators B, 78, 303-309.

Di Natale, C., Paolesse, R., Macagnano, A., Mantini, A., D'Amico, A., Ubigli, M., Legin, A., Lvova, L., Rudnitskaya, A., Vlasov, Y. (2000). Application of a combined artificial olfaction and taste system to the quantification of relevant compounds in red wine. Sens. Actuators B, 69, 342-347.

Dickert, F.L., Hayden, O., Zenkel, M.E. (1999). Detection of volatile compounds with mass-sensitive sensor arrays in the presence of variable ambient humidity. Anal. Chem., 71, 1338-1341.

Dzyadevych, S., Arkhypova, V.N., Korpan, Y.I., El'skaya, A.V., Soldatkin, A.P., Jaffrezic-Renault, N., Martelet, C. (2001). Conductometry formaldehyde sensitive biosensor with specifically adapted analytical characteristics. Anal. Chim. Acta, 445, 47-55.

Ensor, D.R. (1989). The contribution of flavour chemistry to the food industry In: Flavour Chemistry of Lipid Foods, p. 1-12. D.B. Min and T.H. Smouse (Eds.). The American Oil Chemists' Society, Champaign.

Ferrari, V., Marioli, D., Taroni, A., Ranucci, E. (2000). Multisensor array of mass microbalances for chemical detection based on resonant piezo-layers of screen-printed PZT. Sens. Actuators B, 68, 81-87.

Ferreira, L.S., De Souza, M.B., Folly, R.O.M. (2001). Development of an alcohol fermentation control system based on biosensor measurements interpreted by neural networks. Sens. Actuators B, 75, 166-171.

Freudenberg, J., von Schickfus, M., Hunklinger, S. (2001). A SAW immunosensor for operation in liquid using a $\mathrm{SiO}_{2}$ protective layer. Sens. Actuators B, 76, 147-151.

Fukui, K., Katsuki, A. (2000). Improvement of humidity dependence in gas sensor based on $\mathrm{SnO} 2$. Sens. Actuators B, 65, 316-318.

García Pinto, C., Fernández Laespada, M.E., Pérez Pavón, J.L., Moreno Cordero, B. (2001). Electronic olfactometry. A new tool in analytical chemistry. Química Analítica, 20, 3-11.

Gardner, J.W., Bartlett, P.N. (1994). A brief history of electronic noses. Sens. Actuators B, 18-19, 211-220.
Gardner, J.W., Craven, M., Dow, C. Hines, E.L. (1998). The prediction of bacteria type and culture growth phase by an electronic nose with a multi-layer perceptron network. Meas. Sci. Technol., 9, 120-127.

Gardner, J.W., Hines, E.L., Wilkinson, M. (1990). Application of artificial neural networks to an electronic olfactory system. Meas. Sci. Technol., 1, 446-451.

Gardner, J.W., Shurmer, H.V., Tan, T.T. (1992). Application of an electronic nose to the discrimination of coffees. Sens. Actuators B, 6, 71-75.

González Martín, Y., Pérez Pavón, J.L., Moreno Cordero, B., García Pinto, C. (1999). Classification of vegetable oil by linear discriminant analysis of Electronic Nose data. Anal. Chim. Acta, 384, 83-94.

Göpel, W. (2000). From electronic to bioelectronic olfaction, or: from artificial "moses" to real noses. Sens. Actuators B, 65, 70-72.

Griffiths, D., Hall, G. (1993). Biosensors-What real progress is being made? Trends Biotechnol., 11, 122-130.

Guadarrama, A., Fernández, J.A., Íñiguez, M., Souto, J., de Saja, J.A. (2001). Discrimination of wine aroma using an array of conducting polymer sensors in conjunction with solid-phase micro-extraction (SPME) technique. Sens. Actuators B, 77, 401-408.

Gutiérrez, F.J., Fontecha, J.L., Horrillo, M.C., Sayago, I., Fernández, M.J., Gómez-Espinosa, R., Cané, C., Grácia, I. (2000). Microsensores de gases basados en ondas acústicas superficiales. Proceeding Congreso TEDEA, Almagro (Ciudad Real, Spain) 26-9-2000.

Gutiérrez-Osuna, R., Nagle, H.T. (1999). A method for evaluating data-preprocessing techniques for odor classification with an array of gas sensors. IEEE Trans. Syst. Man Cyber., 29, 626-632.

Hatfield, J.V., Covington, J.A., Gardner, J.W. (2000). GasFETs incorporating conducting polymers as gate materials. Sens. Actuators B, 65, 253-256.

Hatfield, J.V., Neaves, P., Hicks, P.J., Persaud, K., Travers, P. (1994). Towards an integrated electronic nose using conducting polymer sensors. Sens. Actuators B, 18-19, 221-228.

Hermle, T, Weimar, U., Mitrovics, J., Rosenstiel, W., Göpel, W. (1999). Feature extraction for a hybrid gas sensing system In: Electronic Noses \& Sensor Array Based System, Design and Applications, p. 97-102. W.J. Hurst (Ed.), Technomic Co, Inc., Lancaster, PA.

Herrmann, F., Hahn, D., Büttgenbach, S. (1999). Separate determination of liquid density and viscosity with sagittally corrugated Love-mode sensors. Sens. Actuators A, 78, 99-107.

Hirschfelder, M., Hanrieder, D., Ulrich, D. (1998). Discrimination of strawberry varieties by a gas sensor array in correlation with human sensory evaluation. Semin. Food Anal., 3, 27-36.

Hodgins, D. (1997). The electronic nose: Sensor array-based instruments that emulate the human nose In: Techniques for Analyzing Food Aroma, p. 331-371. R. Marsili (Ed.), Marcel Dekker Inc., New York.

Hong, S.K. (1999). Compensation of nonlinear thermal bias drift of Resonant Rate Sensor using fuzzy logic. Sens. Actuators A, 78, 143-148.

liyama, S., Yahiro, M., Toko, K. (2000). Measurements of soy sauce using taste sensor. Sens. Actuators $B, 66$, 205-206.

Ivarsson, P, Holmin, S., Höjer, N.E., Krantz-Rülcker, C., Winquist, F. (2001). Discrimination of tea by means of a voltammetric electronic tongue and different applied waveforms. Sens. Actuators B, 76, 449-454. 
Kato, K., Kato, Y., Takamatsu, K., Udaka, T., Nakahara, T., Matsuura, Y., Yoshikawa, K. (2000). Toward the realization of an intelligent gas sensing system utilizing a non-linear dynamic response. Sens. Actuators B, 71, 192-196.

Keller, P.E. (1999). Physiologically inspired pattern recognition for electronic noses. Proceedings of the SPIE, 3722, No. 13.

King, W.H. JR. (1964). Piezoelectric sorption detector. Anal. Chem., 36, 1735-1739.

Kohl, D., Heinert, L., Bock, J., Hofmann, Th., Schieberle, P. (2000). Systematic studies on responses of metal-oxide sensor surfaces to straight chain alkanes, alcohols, aldehydes, ketones, acids and esters using the SOMMSA approach. Sens. Actuators B, 70, 43-50.

Köhler, S., Bachmann, T.T., Schmitt, J., Belkin, S., Schmid, R.D. (2000). Detection of 4-chlorobenzoate using immobilized recombinant Escherichia coli reporter strains. Sens. Actuators B, 70, 139-144.

Kondratowicz, B., Narayanaswamy, R, Persaud, K.C. (2001). An investigation into the use of electrochromic polymers in optical fibre gas sensors. Sens. Actuators $B, 74,138-144$.

Koul, S., Chandra, R., Dhawan, S.K. (2001). Conducting polyaniline composite: A reusable sensor material for aqueous ammonia. Sens. Actuators B, 75, 151-159.

Kress-Rogers, E. (1997). Biosensors and electronic noses for practical application In: Handbook of Biosensors and Electronic Noses. Medicine, Food and Environment, p. 3-39. E. Kress-Rogers (ed). CRC Press: Boca Raton, FL.

Lang, A.C., Fleischer, M., Meixner, H. (2000). Surface modifications of Ga2O3 thin film sensors with $\mathrm{Rh}, \mathrm{Ru}$ and Ir clusters. Sens. Actuators B, 66, 80-84.

Lazzerini, B., Maggiore, A. Linguistic fuzzy classification of olfactive signals. 1998 IEEE International Conference on fuzzy systems proceedings. IEEE World Congress on Computational Intelligence (CAT No. 98CH36228), p. 1518-1523. Vol. 2.

Legin, A., Rudnitskaya, A., Vlasov, Y., Di Natale, C., Mazzone, E., D’Amico, A. (2000). Application of electronic tongue for qualitative and quantitative analysis of complex liquid media. Sens. Actuators B, 65, 232-234.

Li, D., Ma, M. (2000). Surface acoustic wave microsensors based on cyclodextrin coatings. Sens. Actuator B, 69, 75-84.

Liao, J.D., Wang, S-H., Hsu, D-J. (2001). Studies on the early detection of wastewater's toxicity using a microbial sensing system. Sens. Actuators B, 72, 167-173.

Lillis, B., Grogan, C., Berney, H., Lane, W.A. (2000). Investigation into immobilisation of lactate oxidase to improve stability. Sens. Actuators B, 68, 109-114.

Liu, J., Li, G. (2000). Applications of biosensors for diagnostic analysis and bioprocess monitoring. Sens. Actuators B, 65, 26-31.

Liu, W., Ma, W., Li, L., Li, J. (2000). The temperature change in SnO2- based gas sensors during sensing reaction. Sens. Actuators B, 66, 222-224.

Lucas, Q., Poling, J., Benincasa, V. (1998). Analysis with a hybrid system QCM/CP/MOS. Semin. Food Anal., 3, 53-58.

Lucklum, R., Hauptmann, P. (2000). The quartz crystal microbalance: mass sensitivity, viscoelasticity and acoustic amplification. Sens. Actuators B, 70, 30-36.

Lundström, I., Shivaraman, M.S., Svensson, C., Lundkvist, L (1975). Applied Physics Letters, 26, 55.
Lundström, I., Spetz, A., Winquist, F., Ackelid, U., Sundgren, H. (1990). Catalytic metals and field-effect devices - a useful combination. Sens. Actuators B, 1, 15-20.

Lüth, H., Thust, M., Steffen, A., Kordos, P., Schöning, M.J. (2000). Biochemical sensors with structured and porous silicon capacitors. Sens. Actuators B, 69, 104-108.

Luzuriaga, D.A., Balaban, M.O. (1999). Electronic nose odor evaluation of salmon fillets stored at different temperatures. In: Electronic Noses \& Sensor Array Based System, Design and Applications. W. J. Hurst (Ed.), Technomic:Lancaster, PA, pp. 219-279.

Magan, N., Pvlou, A., Chrysanthakis, I. (2001). Milk-Sense: $A$ volatile sensing system recognises spoilage bacteria and yeast in milk. Sens. Actuators B, 72, 28-34.

Masila, M., Breimer, M., Sadik, O. A. (1999). Strategies for improving the analysis of volatile organic compounds using GC-based electronic nose In: Electronic Noses \& Sensor Array Based System, Design and Applications, p. 26-42. W.J. Hurst (Ed.), Technomic Co, Inc., Lancaster, PA.

McGill, R.A., Nguyen, V.K., Chung, R., Shaffer, R.E., DiLella, D., Stepnowski, J.L., Mlsna, T.E., Venezky, D.L., Dominguez, D. (2000). The "NRL-SAWRHINO": a nose for toxic gases. Sens. Actuators B, 65, 10-13.

Ménil, F., Coillard, V., Lucat, C. (2000). Critical review of nitrogen monoxide sensors for exhaust gases of lean burn engines. Sens. Actuators B, 67, 1-23.

Middelhoek, S. (2000). Celebration of the tenth transducers conference: The past, present and future of transducer research and development. Sens. Actuators A, 82, 2-23.

Mielle, P. (1996). Electronic noses: Towards the objective instrumental characterization of food aroma. Trends Food Sci. Technol., 7, 432-438.

Mielle, P., Marquis, F., Latrasse, C. (2000). Electronic noses: specify or disappear. Sens. Actuators B, 69, 287-294.

Montedoro, G. F., Servili, M., Baldioli, M., Miniati, E. (1992). Simple and hydrolyzable phenolic compounds in olive oil: 1. Their extraction, separation, and quantitative and semiquantitative evaluation by HPLC. J. Agric. Food Chem. 40, 1571-1576.

Morales, M.T., Aparicio, R., Gutiérrez, F. (1992). Técnicas de aislamiento y concentración de volátiles de aceites vegetales. Grasas Aceites, 43, 164-173.

Morales, M.T., Tsimidou, M. (2000). The role of volatile compounds and polyphenols in olive oil sensory quality. In: Handbook of Olive Oil: Analysis and Properties, p. 393-458. J. Harwood and R. Aparicio (Eds.), Aspen:Gaithersburg, MA.

Morimitsu, M., Ozaki, Y., Suzuki, S., Matsunaga, M. (2000). Effects of surface modification with platinum and ruthenium on temperature and humidity dependence of SnO2-based CO gas sensors. Sens. Actuators B, 67, 184-188.

Muenchmeyer, W., Walte, A., Matz, G. (2000). Improving electronic noses using a trap and thermal desorption unit. Sens. Actuators B, 69, 379-383.

Müller, C., Nirmaier, T., Rügemer, A., Schickfus, M.v. (2000). Sensitive NO2 detection with surface acoustic wave devices using a cyclic measuring technique. Sens. Actuators B, 68, 69-73.

Nakamoto, T., Nakahira, Y., Hiramatsu, H., Moriizumi, T. (2001). Odor recorder using active odor sensing system. Sens. Actuators B, 76, 465-469.

Nikitin, P.I., Grigorenko, A.N., Beloglazov, A.A., Valeiko, M.V., Savchuk, A.I., Savchuck, O.A., Steiner, G., Kuhne, C., Huebner, A., Salzer, R. (2000). Surface 
plasmon resonance interferometry for micro-array biosensing. Sens. Actuators A, 85, 189-193.

Nomura, T., Saitoh, A., Horikoshi, Y. (2001). Measurement of acoustic properties of liquid using liquid flow SH-SAW sensor system. Sens. Actuators B, 76, 69-73.

Ortega, N., Busto, M.D., Perez-Mateos, M. (1998) Optimisation of -glucosidase entrapment in alginate and polyacrilamide gels. Bioresour. Technol., 64, 105-111.

Palleschi, G., Cubadda, R. (2001). Electrochemical biosensors for food analysis and the food industry. Italian J. Food Science, 13, 137-157.

Pardo, M., Niederjaufner, G., Benussi, G., Comini, E., Faglia, G., Sberveglieri, G., Holmberg, M., Lundstrom, I. (2000b). Data preprocessing enhances the classification of different brands of Espresso coffee with an electronic nose. Sens. Actuators B, 69, 397-403.

Pardo, M., Sberveglieri, G., Gardini, S., Dalcanale, E. (2000a). A hierarchical classification scheme for an Electronic Nose. Sens. Actuators B, 69, 359-365.

Partridge, A.C., Harris, P., Andrews, M.K. (1996). High sensitivity conducting polymers sensors. Analyst, 121, 1349-1353.

Paulsson, N, Larsson, E., Winquist, F. (2000). Extraction and selection of parameters for evaluation of breath alcohol measurement with an electronic nose. Sens. Actuators A, 84, 187-197.

Pearce, T.C., Gardner, J.W., Friel, S., Barlett, P.N., Blair, N. (1993). Electronic nose for monitoring the flavour of beers. Analyst, 118, 371-377.

Persaud, K.C., Travers, P.J. Arrays of broad specificity films for sensing volatile chemicals In: Handbook of Biosensors and Electronic Noses. Medicine, Food And Environment, p. 563-592. E. Kress-Rogers (Ed.) CRC Press, Inc. Boca Raton, FL.

Porter, T.L., Eastman, M.P., Pace, D.L., Bradley, M. (2001). Sensor based on piezoresistive microcantilever technology. Sens. Actuators A, 88, 47-51.

Qin, S., Wu, Z., Tang, Z., Song, Y., Zeng, F., Zhao, D. (2000). The sensitivity to SO2 of the SAW gas sensor with triethanolamine modified with boric acid. Sens. Actuators B, 66, 240-242.

Ramos, M.C., Torijas, M.C., Navas Díaz, A. (2001) Enhanced chemiluminiscence biosensor for the determination of phenolic compounds and hydrogen peroxide. Sens. Actuators B, 73, 71-75.

Reineccius, G. (1993). Biases in analytical flavor profiles introduced by isolation method In: Flavor Measurement, p. 61-67. C.T. Ho and C.H. Manley (Eds.), Marcel Dekker, New York.

Rella, R., Siciliano, P., Quaranta, F., Primo, T., Valli, L., Schenetti, L., Mucci, A., larossi, D. (2000). Gas sensing measurements and analysis of the optical properties of poly[3-(Butylthio) Thiophene] Langmuir-Blodgett films. Sens. Actuators B, 68, 203-209.

Reviejo, A.J., Pingarrón, J.M. (2000). Biosensores electroquímicos. Una Herramienta útil para el análisis medioambiental, alimentario y clínico. Anales de la Real Sociedad Española de Química, 96, 2, 5-15.

Romain, A-C., Nicolas, J., Wiertz, V., Maternova, J., André, $\mathrm{Ph}$. (2000). Use of a simple tin oxide sensor array to identify five malodours collected in the field. Sens. Actuators B, 62, 73-79.

Rong, L., Ping, W., Wenlei, H. (2000). A novel method for wine analysis based on sensor fusion technique. Sens. Actuators B, 66, 246-250.

Saoudi, B., Despas, C., Chehimi, M.M., Jammul, N., Delamar, M., Bessiére, J., Walcarius, A. (2000). Study of DNA adsorption on polypyrrole: Interest of dielectric monitoring. Sens. Actuators B, 62, 35-42.

Sberveglieri, G., Comini, E., Faglia, G., Niederjaufner, G., Benussi, G., Contarini, G., Povolo, M. (1998). A novel electronic nose based on semiconductor thin film gas sensor to distinguish different heat treatments of milk. Semin. Food Anal., 3, 67-76.

Schaak, R.E., Dahlberg, D.B., Miller, K.B. (1999). The electronic nose: studies on the fundamental response and discriminative power of metal-oxide sensors In: Electronic Noses \& Sensor Array Based System, Design and Applications, p. 43-50. W. J. Hurst (Ed.), Technomic Co, Inc., Lancaster, PA.

Schaller, E., Bosset, J. O., Escher, F. (1998). Electronic nose and their application to food. Lebensm.-Wiss. u.-Technol., 31, 305-316.

Schütz, S, Schöning, M.J., Schroth, P., Malkoc, Ü, Weibecker, B., Kordos, P., Lüth, H., Hummel, H.E. (2000). An insect-based BioFET as a bioelectronic nose. Sens. Actuators B, 65, 291-295.

Senillou, A., Jaffrezic-Renault, N., Martelet, C., Cosnier, S. (1999). A miniaturized urea sensor based on the integration of both ammonium based urea enzyme field effect transistor in a single chip. Talanta, 50, 219-226.

Shinohara, H., Kusaka, T., Yokota, E., Monden, R., Sisido, M. (2000). Electron transfer between redox enzymes and electrodes through the artificial redox proteins and its application for biosensors. Sens. Actuators B, 65, 144-146.

Shurmer, H.V., Gardner, J.W. (1992). Odour discrimination with an electronic nose. Sens. Actuators B, 8, 1-11.

Simon, I, Bârsan, N., Bauer, M., Weimar, U. (2001). Micromachined metal oxide gas sensors: opportunities to improve sensor performance. Sens. Actuators $B, 73$, 1-26.

Sinesio, F., Di Natale, C., Quaglia, G.B., Bucarelli, F.M., Moneta, E., Macagnano, A., Paolesse, R., D'Amico, A. (2000). Use of electronic nose and trained sensory panel in the evaluation of tomato quality. J. Sci. Food Agric., 80, 63-71.

Singh, S., Hines, E.L., Gardner, J.W. (1996). Fuzzy neural computing of coffee and tainted water data from an electronic nose. Sens. Actuators B, 30, 3, 190-195.

Slater, J.M., Paynter, J., Watt, E.J. (1993). Multi-layer conducting polymer gas sensor arrays for olfactory sensing. Analyst, 118, 379-384.

Slater, J.M., Watt, E.J., Freeman, N.J., May, I.P., Weir, D.J. (1992). Gas and vapour detection with poly(Pyrrole) gas sensors. Analyst, 117, 1265-1270.

Spetz, A., Winquist, F., Sundgren, H., Lundström, I. (1992). Field effect gas sensors In: Gas sensors, p. 219-279. G. Sberveglieri (Ed.), Kluwer Academic:Dordrecht, Germany.

Spetz, A.L., Tobias, P., Unéus, L., Svenningstorp, H., Ekedahl, L-G, Lundström, I. (2000). High temperature catalytic metal field effect transistors for industrial applications. Sens. Actuators B, 70, 67-76.

STATISTICA. Users Guide, release 5.5; Statsoft: Tulsa, OK, 2000.

Stetter, J.R., Strathmann, S., McEntegart, C., Decastro, M., Penrose, W.R. (2000). New sensor arrays and sampling systems for a modular electronic nose. Sens. Actuators B, 69, 410-419.

Su, X., Low, S., Kwang, J., Chew, V.H.T., Li, S.F.Y. (2001). Piezoelectric quartz crystal based veterinary diagnosis for Salmonella enteritidis infection in chicken and egg. Sens. Actuators B, 75, 1-2, 29-35.

Takada, T. (2000). Temperature drop of semiconductor gas sensor when exposed to reducing gases-simultaneous 
measurement of changes in sensor temperature and in resistance. Sens. Actuators B, 66, 1-3.

Tan, C.K., Blackwood, D.J. (2000). Interactions between polyaniline and methanol vapour. Sens. Actuators B, 71, 184-191.

Tempelman, L.A., King, K.D., Anderson, G.P., Ligler, F.S. (1996). Quantitating Staphylococcal enterotoxin B in diverse media using a portable fiber-optic biosensor. Anal. Biochem., 233, 50-57.

Toko, K. (2000). Taste sensor. Sens. Actuators B, 64, 205-215.

Tong, X., Zhang, D. (1999). Novel propagation direction of quasi-longitudinal leaky surface acoustic wave on quartz and its potential as liquid sensors. Sens. Actuators A, 78, 160-162.

Werlein, H-D. (2001). Discrimination of chocolates and packaging materials by an electronic nose. Eur. Food Res. Technol., 212, 529-533.

White, S.F., Turner, A.P.F. (1997). Enzymes, cofactors, and mediators In: Handbook of Biosensors and Electronic Noses. Medicine, Food and Environment, p. 43-57. E. Kress-Rogers (Ed). CRC Press: Boca Raton, FL.

Wilson, D.M., Dunman, K., Roppel, T., Kalim, R. (2000). Rank extraction in tin-oxide sensor arrays. Sens. Actuators B, 62, 199-210.

Winquist, F., Lundström, I., Bergkvist, H. (1990). Ethylene production from fruits measured by a simple field-effect structure and compared with a gas chromatographic method. Anal. Chim. Acta, 231, 93-100.

Winquist, F., Lundström, I., Wide, P. (1999). The combination of an electronic tongue and an electronic nose. Sens. Actuators B, 58, 512-517.

Xu, Y., Zhou, X., Sorensen, T. (2000). Oxygen sensors based on semiconducting metal oxides: an overview. Sens. Actuators B, 65, 2-4.

Zhang, G., Liu, M. (2000) Effect of particle size and dopant on properties of SnO2-based gas sensors. Sens. Actuators B, 69, 144-152.

Zhao, S., Sin, J.K. O., Xu, B., Zhao, M., Peng, Z., Cai, H. (2000). A high performance ethanol sensor based on field-efecct transistor using a $\mathrm{LaFeO} 3$ nano-crystalline thin-Film as a gate electrode. Sens. Actuators B, 64, 83-87.

Zimmermann, C., Rebière, D., Déjous, C., Pistré, J., Chastaing, E., Planade, R. (2001). A love-wave gas sensor coated with functionalized polysiloxane for sensing organophosphorus compounds. Sens. Actuators B, 76, 86-94.

Zondervan, C., Muresan, S., de Jonge, H.G., van Velzen, E.U.T., Wilkinson, C., Nijhuis, H.H., Leguijt, T. (1999). Controlling Maillard reactions in the heating process of blockmilk using an electronic nose. J. Agric. Food Chem., 47, 4746-4749. 